\title{
Lampblack Pollution and Control Measures in the Canteen of a University in Ji'nan
}

\author{
Ting LI \\ School of Thermal Engineering \\ Shandong Jianzhu University \\ Jinan, Shandong, 250101, China \\ e-mail: liting0939@163.com
}

\author{
Xupeng WEI \\ School of Thermal Engineering \\ Shandong Jianzhu University \\ Jinan, Shandong, 250101, China \\ e-mail: 719059552@qq.com
}

\begin{abstract}
The environment is usually changed to benefit human life. However, advances come with a significant environment cost. Our health is suffering severe persecution that created by burning fossil fuels and pour polluting chemical waste into the living environment. Canteen is an important place for college students to eat and socialize, and the air quality of it has a great impact on the health of teachers and students. In this paper, we measured the concentration of acrolein which is the main components of the lampblack in the dining room, and we also put forward two kinds of control measures.
\end{abstract}

\section{Keywords-canteen; lampblack; acrolein; control measures}

\section{INTRODUCTION}

\section{A. General Situation of Indoor Pollution}

With the continuous development of society, the activities of people, especially for urban residents, tend to indoors for mental and light physical labor. At the same time, because of the extensive using of the building materials and the internal chemical supplies of the buildings, indoor air quality has become an important factor which threaten people's health. Indoor air pollution makes people appeared many new conditions, in particular, volatile organic compounds (VOCs) on the human liver and nervous system have a certain damage, causing serious harm to human health. As early as 1980, the World Health Organization called the disease which caused by the lack of fresh air as Sick Building Syndrome (SBS).

\section{B. Research Status at Home and Abroad}

As people's requirements on the indoor air quality continue to increase, more and more experts and scholars no matter who come from domestic or foreign have already begun to study the indoor environment and pollution. As early as $1988-1989$, Shicong Qiu and Guifu Chen had a survey on the ventilation and respiratory health in the room in which there has children. They also made simulations for the improvement measures, and they found that the number of ventilation per hour in the room was negatively correlated with the rate of respiratory symptoms in children [1]. In 1996, Haihong Hu and Xiudao Dai [2] have made an analysis about the effects of indoor air pollution on the health and how to control the pollutant. Japan's Hisao Chikara [3] et al, have studyed the concentration and sources of indoor volatile organic compounds (VOCs), and its effects on human health in 2009. In recent years, the research on indoor air pollutants are more in-depth, Shenglong Sun, Yan Dong et al, have detected and researched 9 kinds of indoor VOCs pollution, they concluded that indoor concentrations of organic pollutants are closely related to ambient temperature, indoor ventilation, and interior decoration [4]. Yuanyuan Cao and others made a deep analysis about the current indoor pollution control technology problems, and put forward the future development of indoor air purification technology [5]. In short, the research on indoor air pollution and control is in the ascendant.

In this paper, we have made some research about the lampblack in a university canteens in Ji'nan, and the main component of the lampblack - acrolein has been tested in the different periods. From this test we found that the concentration of acrolein is closely related to the time of food cooking.

\section{LAMPBLACK POLLUTION AND CONTROL MEASURES IN THE CANTEEN}

Since the implementation of the policy of university enrollment expansion in 1999, the number of colleges and universities in China has reached 2000, with 35 million students enrolled in higher education. University is no longer just to provide textbook learning place to students, it is more an important place to participate in social activities and carry out cultural exchanges. Canteen as the place to supply teachers and students with food and the main place of the party, its internal environment have a great impact of people.

Edible oil and food after high temperature heating generated fumes into the human body's respiratory tract, that will lead to disease, which known as smoke syndrome. Patients often appear loss of appetite, upset, lack of energy, lethargy, fatigue, weakness and other symptoms. In addition, the lampblack contains a carcinogen called benzopyrene which can induce lung cancer if long-term inhalation.

\section{A. General Situation of a University Canteen in Ji'nan}

The canteen has a total of three layers. Among them, the first and the second floor are the main dining area for students, the third floor is mainly for students, teachers and other staff to provide party dinner places. This article mainly studies the first floor and the second floor of the canteen, from the Figure 1 we can see, their layout is similar. The southern hall (excluding kitchen) is 60 meters long and 25 meters wide. The eastern hall is 55 meters long and 30 meters wide. And the floor is about 4 meters high. The total 
floor area of the dining area of 2400 square meters, can accommodate about 2000 people. According to the school curriculum, students began to eat in the canteen at about 7:00. At noon, students 12:00 after school, and then directly to the canteen to eat. In the evening, the students eat time is relatively dispersed, mainly concentrated in the 17:00-19:00.
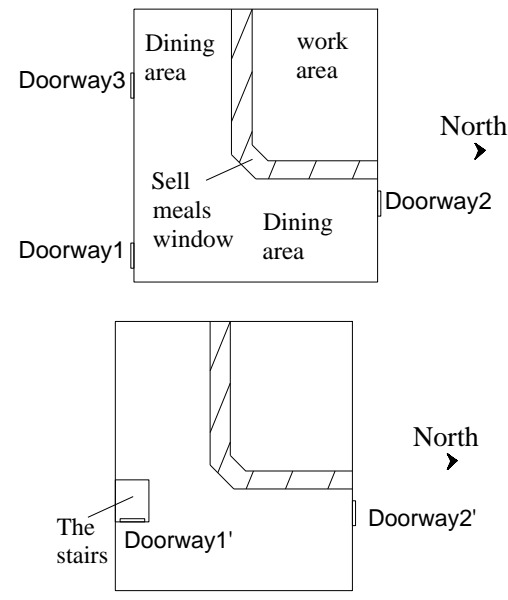

Figure 1. Schematic plan view of the first floor and the second floor

\section{B. The Changing Trend of Lampblack in Canteen}

As mentioned above, the detection object of this paper is acrolein--the main pollutant in the lampblack. The concentrations of acrolein in the monitoring points is continuously detected for 5 days (Monday to Friday) in four time periods. The location of monitoring points mainly in the dining area, the layout shown in Figure 2, Among them, the monitoring point 6 for the outdoor control point, monitoring point 4 for the dining personnel to buy food area, monitoring point 3 for the aisle, the other monitoring points are dining area. The time periods were 8:30, 12:00, 15:30, 18:00, and then, we took the average value of the monitoring points in the canteen to get the curve of the change of the acrolein's concentration with time, as shown in Figure 3.

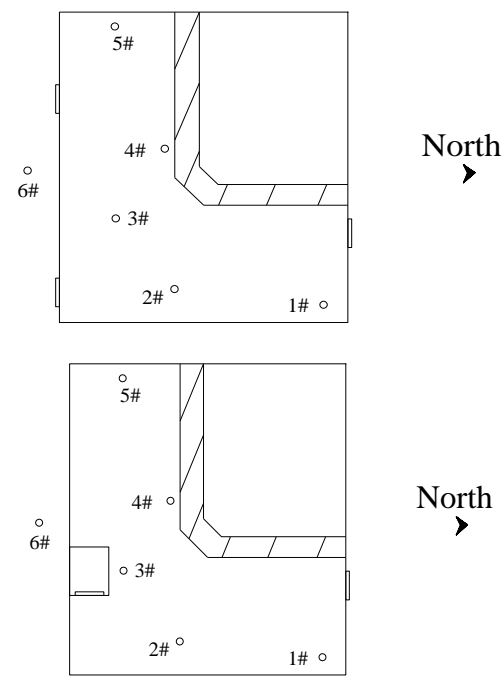

Figure 2. Distribution of monitoring points of concentration of acrolein

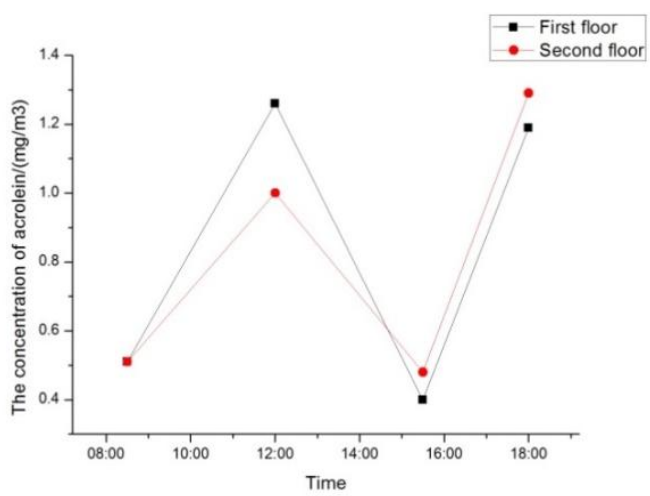

Figure 3. The change of the concentration of the acrolein in the canteen with time

From Figure 3 we can see that the concentration of the acrolein in the dining room changes with time, the concentration of the acrolein and the number of cooking activities have a close relationship. At 8: 30 and 15: 30, the cooking activities are relatively small, and the concentration of acrolein is significantly lower. 12:00 and 17: 30 is the two dining peak, and in this two time periods of the canteen within the acrolein concentration increased significantly.

\section{Control Measures of LAMPBlack Pollution IN CANTEEN}

\section{A. The Source Control}

We need to control the source of the lampblack generated firstly if we want to reduce the amount of the lampblack in the canteen, and the following aspects need to be done:

(1) Do not make oil overheating, the temperature of oil should not exceed $200^{\circ} \mathrm{C}$ (to the limit of smoking),

(2) It's best to not use the repeated frying oil, if we repeatedly use the edible oil that have been fried many times, the oil itself will be contained carcinogenic substances, and also its product of the lampblack carcinogens are more harmful,

(3) Try to use steaming, boiling and other cooking methods,

(4) In the cooking process, keeping the cooker hood open, when cooking is over, after 10 minutes turn off the hood,

(5) Do not do the cooking, especially do not frying food while the students are eating.

In the meantime, for producing the same energy, the different types of fuel resulting in different emissions of pollutants, the fuel that produce the least contaminants are electricity, followed by natural gas, we recommend that the canteen can increase the use of natural gas, while if have the conditions, it can choose to use electric cooker.

\section{B. The Ventilation Settings}

Although we have done some control about the source of the lampblack produced, a large number of oil fumes are still unavoidable due to the inherent nature of the canteen itself, it is very important to do a good job in the canteen kitchen ventilation. 
Kitchen ventilation volume is composed of two parts, that is, partial discharge and total exhaust air volume.

The exhaust air volume for full ventilation can be calculated by heat balance, as in Eq.(1).

$$
L=\frac{Q}{0.348\left(t_{o}-t_{i}\right)}
$$

$L$--The amount of ventilation required,

$t_{o}$--The calculation temperature of indoor exhaust air,

$t_{i}$--The calculation temperature of indoor ventilation,

$Q$--The total amount of heat in the kitchen.

According to the wind speed of the air exhaust hood to calculate the local exhaust air volume, as in Eq.(2). At the same time, we should pay attention to suction speed of the hood's mouth should not be less than $0.5 \mathrm{~m} / \mathrm{s}$.

$$
L_{j}=1000 U \cdot H
$$

$L_{j}$--The exhaust amount of the exhaust hood, $\mathrm{m} 3 / \mathrm{h}$,

$U$--The surrounding length of the exhaust hood(side of the wall is not calculated), $\mathrm{m}$,

$H$--The distance from the cover mouth to the cover, m, (The actual project is not more than $1.8 \mathrm{~m}$ is appropriate).

Because Ji'nan belongs to the cold area, considering the energy conservation, the kitchen of the canteen can be used the local exhaust hood. Moreover, when dividing the local exhaust hood and exhaust port, we should divide the similar properties to the same load ventilation system. And in the same time, we should try to make the local resistance of each exhaust point close, then we need to add a control valve on the wind pipe if the resistance is different.

\section{CONCLUSION}

With the improvement of living standards, the quality of the indoor air has been getting more and more attention. According to the investigation of the people, the lampblack pollution has become one of the important pollutants which harm human health. In this paper, we measured the concentration of acrolein which is the main components of the lampblack in the dining room, and put forward two kinds of control measures, that is, the methods to control the source of lampblack generation and improving the ventilating facilities in the kitchen.

\section{REFERENCES}

[1] Shicong Qiu, Guifu Chen. Study on indoor air quality and health effects of ventilation and ventilation [J]. Environmental Science, 1992 (3): 29-32.

[2] Haihong Hu, Xiudao Dai. Effect and control of indoor air pollution on health [J]. Chinese Journal of Public Health, 1996, 12 (1): 13-14.

[3] Chikara Hisao, Iwamoto Shinji, Yoshimura Takesumi. Indoor air pollution of volatile organic compounds: indoor/outdoor concentrations, sources and exposures [J]. Nihon Eiseigaku Zasshi, 2009, Vol.64 (3), pp.683-8.

[4] Shenglong Sun, Yan Dong, Tingting Sun, et al. Investigation and Study on indoor organic volatile organic pollutants (VOCS) pollution in Northeast China [J]. Journal of Northeast Normal University: Natural Science Edition, 2009, 41 (1): 117-122.

[5] Yuanyuan Cao, Ting Guo, Chunmei Geng, et al. The new situation of indoor air pollution and pollution control technology [J]. environmental science and technology, 2013 (S2): 229-231.

[6] Shijie Song. Design of large scale dining room kitchen ventilation design [J]. forestry science and technology information, 2005, 37 (4): 32-33.. 